\title{
Selektivitas Membran Hibrid PS/DMAc/PEG-Lempung dan PS/DMAc/Lempung Dalam Non Pelarut Campuran $\mathrm{H}_{2} \mathrm{O} / 2$-propanol
}

\author{
Zaiyar* \\ ${ }^{2}$ Jurusan Teknik Sipil, Sekolah Tinggi Teknologi Pekanbaru \\ *Coresponding Author : zaiyar68@yahoo.co.id
}

\begin{abstract}
Abstrak
Selektivitas membran hibrid PS/DMAc/PEG-Lempung yang menggunakan polimer polisulfon (PS), pelarut dimetil asetamida (DMAc) zat aditif polietilen glikol (PEG) dan lempung dan PS/DMAc/Lempung yang tanpa menggunakan PEG ditentukan dari kemampuan kedua membran dalam merejeksi dekstran. Perbandingan konsentrasi retentat didalam permeat dan umpan ditentukan spektrofotometri $U V$-Vis. Selektivitas membran hibrid PS/DMAc/PEG-Lempung sebesar 97,06\%, sedangkan membran hibrid PS/DMAc/Lempung sebesra $82,77 \%$. Pengujian selektivitas rata-rata kedua membran menggunakan uji t menunjukkan perbedaan yang signifikan. Perbedaan komposisi dari polietilen glikol dan lempung mempengaruhi selektivitas dari membran yang dihasilkan . Membran hibrid PS/DMAc/PEG-Lempung lebih selektif dalam merejeksi dekstran.karena jumlah, ukuran dan distibusi pori lebih baik dibandingkan membran PS/DMAc/Lempung
\end{abstract}

Kata Kunci : Selektivitas,Membran hibrid, Rejeksi, Signifikan

\section{Pendahuluan}

Membran hibrid PS/DMAc/PEG-Lempung dan PS/DMAc/Lempung adalah membran yang dibuat dengan cara menambahkan bahan anorganik lempung ke dalam matriks polimer polisulfon. Pencampuran kedua bahan ini bertujuan mengatasi keterbatasan dari membran yang dihasilkan.

Membran yang terbuat dari bahan polimer mempunyai selektivitas rendah, tidak stabil pada suhu dan $\mathrm{pH}$ ekstrim, serta mengalami penggembungan dan terdekomposisi dalam pelarut organik. Sedangkan membran anorganik aplikasinya terbatas, rapuh dan mahal (Zulfikar, et al., 2006)

Pada penelitian sebelumnya, telah dilakuan kajian terhadap permeabilitas membran hibrid polisulfon-lempung (Zaiyar, 2014). Pada penelitian ini akan dilakukan kajian terhadap selektivitas membran hibrid PS/DMAc/PEG-Lempung dan PS/DMAc/Lempung karena kinerja berkaitan dengan permeabilitas dan selektivitas. Membran hidrid mempunyai kinerja pemisahan disebabkan kandungan bentonit dan monmorilonit yang berasal dari lempung (Defontaine et al., 2010)
Berdasarkan penelitian tersebut, penulis tertarik melakukan kajian penelitian dengan membandingkan perbedaan komposisi lempung dan penggunaan polietilen glikol (PEG) dalam pembuatan membran hibrid dalam kaitannya dengan selektivitas membrannya.

Polisulfon dipilih sebagai material organik polimer karena memiliki kestabilan mekanik, termal dan kimia yang baik (Anadao et al, 2010). Lempung yang digunakan berasal dari Desa Pallas Rumbai. Lempung ini memiliki kandungan $\mathrm{SiO} 2$-sekitar 58\% (Nadarlis, 2012), sedangkan PEG berfungsi sebagai porogen untuk meningkatkan porositas dari membran yang dihasilkan. Dimetil Acetamida merupakan pelarut yang baik untuk melarutkan polisulfon. Non pelarut yang digunakan sebagai media koagulasi adalah campuran 2-propanol-air.

Selektivitas membran merupakan ukuran kemampuan membran menahan atau melewatkan suatu molekul terlarut. Selektivitas membran tergantung pada interaksi antar permukaan dengan molekul, ukuran molekul, dan ukuran pori membran. Selektivitas dinyatakan sebagai koefisien rejeksi yang dilambangkan dengan $\mathrm{R}$, yaitu 
fraksi konsentrasi zat yang tertahan oleh membran. Menurut Mulder (1996), rejeksi suatu zat padat terlarut (solute) ditentukan oleh persamaan 1

$R=\frac{C b-C p}{C b} \times 100 \%=1-\frac{C p}{C b} \times 100 \%$

Dalam hal ini, $C p$ adalah konsentrasi zat terlarut di dalam permeat dan $\mathrm{Cb}$ adalah ratarata konsentrasi zat terlarut di dalam umpan (feed) dan retentat.

Pengukuran konsentrasi zat terlarut di dalam umpan, permeat dan retentat ditentukan dengan metode spektrofotometri sinar tampak.

Spektrofotometri merupakan salah satu cara analisis kimia berdasarkan pada penyerapan sinar monokromatis oleh suatu larutan berwarna, yaitu dengan cara mengukur intensitas sinar yang diserap oleh larutan berwarna pada panjang gelombang $(\lambda)$ tertentu dengan menggunakan monokromator prisma atau kisi difraksi dengan detektor (Khopkar, 1990). Intensitas sinar yang diserap larutan diukur berdasarkan hubungan Lambert-Beer mengikuti persamaan 2 .

$A=a b c$ atau $A=\varepsilon b c \ldots .$.

Dalam hal ini, A adalah absorbansi, a adalah tetapan absorptivitas (jika c dalam ppm), b adalah panjang jalan sinar melewati sampel $(\mathrm{cm}), \mathrm{c}$ adalah konsentrasi larutan dan $\varepsilon$ adalah tetapan absorptivitas molar (jika c dalam molar).

Pengukuran rejeksi dalam penelitian ini bertujuan untuk mengetahui daya tolak membran terhadap dekstran. Nilai $\mathrm{R}$ bervariasi antara $0-100 \%$, jika $\mathrm{R}=100 \%$ berarti terjadi pemisahan sempurna (membran semipermeabel ideal), sedangkan nilai $\mathrm{R}=0 \%$ berarti partikel semua lolos dari membran. Faktor-faktor yang mempengaruhi nilai rejeksi membran antara lain: ukuran partikel yang dapat melewati membran, interaksi antara membran dengan umpan, ukuran pori dan porositas membran. Membran yang memiliki ukuran pori kecil akan memberikan tolakan yang lebih besar dibandingkan membran yang mempunyai ukuran pori lebih besar (Mulder,1996).

\section{Metode Penelitan}

\subsection{Alat dan Bahan}

Alat-alat yang digunakan pada penelitian ini adalah: Sel berpengaduk, ayakan 200 mesh, pengaduk magnetik, batang stainless steel,

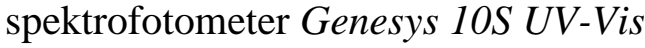

Bahan-bahan kimia yang digunakan pada penelitian ini adalah : Polisulfon UDEL P3500 (Solvay Advance Polymer), lempung Desa Palas $\left(\mathrm{SiO}_{2}=58 \%\right)$, N,N Dimetil asetamida (DMAc) (Merck), polietilen glikol (PEG) 4000, dekstran 400-500 kDa, dekstran 35-45 kDa, dekstran 8,5-11,5 kDa (average mol.Wt), $\mathrm{H}_{2} \mathrm{SO}_{4}$ pekat, Fenol $5 \%$.

\subsection{Pembuatan Membran Hibrid}

Pada penelitian ini, membran hibrid PS/DMAc/PEG-Lempung dan PS/DMAc/Lempung dibuat secara inversi fase. Membran hibrid PS/DMAc/PEGLempung dibuat dengan cara : melarutkan $18 \%$ polisulfon dalam $64 \%$ dimetil formamida (DMAc), 9\% lempung, dan 9\% polietilen glikol (PEG). Membran hibrid PS/DMAc/Lempung juga menggunakan polisulfon dan DMAc dalam persentase sama tetapi tanpa menggunakan PEG dan lempungnya adalah $18 \%$. Masing-masing matriks polimer membran hibrid secara terpisah dilarutkan menggunakan pengaduk magnetik pada temperatur kamar selama 15 jam sampai larutan homogen. Larutan ini, selanjutnya akan menjadi larutan tuang polimer. 
Larutan tuang polimer didiamkan selama 3 jam untuk menghilangkan gelembung udara yang terperangkap di dalam larutan sebelum dilakukan pencetakan (Tweddle et al., 1994). Larutan tuang polimer masingmasing selanjutnya ditebar di atas plat kaca yang telah diolesi aseton lalu diratakan dengan batang stainless steel hingga terbentuk lapisan tipis dan dibiarkan selama 5 menit. Kemudian lapisan tipis pada pelat direndam dalam bak koagulasi yang telah berisi campuran non pelarut 2-propanol-air perbandingan (1:1). Proses koagulasi dilakukan selama 5 menit sehingga terbentuklah membrane hibrid PS/DMAc/PEG-Lempung dan PS/DMAc/Lempung terkoagulasi.

\subsection{Kompaksi Membran Hibrid}

Membran hibrid PS/DMAc/PEG-Lempung dan PS/DMAc/Lempung dipotong berbentuk lingkaran dengan diameter sesuai sel berpengaduk. Sebelum melakukan kompaksi, membran hibrid terlebih dahulu direndam dalam air selama 24 jam dengan tujuan untuk menghilangkan sisa pelarut dan non pelarut yang masih tertinggal pada pembuatan membran. Membran ditempatkan pada bagian dasar dari alat membran sel. Selanjutnya sebanyak $200 \mathrm{~mL}$ air dimasukkan ke dalam sel dan sel membran ditutup. Membran dikompaksi pada tekanan 2 bar, selama 2 jam untuk mendapatkan kondisi stabil. Membran yang telah dikompaksi digunakan untuk pengukuran selaktivitas,

\subsection{Pengukuran Selektivitas}

Pengujian selektivitas membran hibrid PS/DMAc/PEG-Lempung ditentukan dari rejeksi membran terhadap dekstran. Dekstran dengan berat molekul (8.5-11.5 $\mathrm{kDa}, \quad 35-45 \mathrm{kDa}$ dan 400-500 kDa) dilarutkan hingga konsentrasinya 100 ppm. Larutan dekstran dimasukkan ke dalam sel berpengaduk yang telah berisi membran, dengan laju adukan $500 \mathrm{rpm}$ pada suhu kamar. Permeat dan retentat pada berbagai tekanan $(1,0 ; 1,5 ; 2,0 ; 3.0$ dan 3,5 bar $)$ ditampung sebanyak $5 \mathrm{~mL}$, begitu juga dengan umpan yang digunakan diambil sebanyak $5 \mathrm{~mL}$. Waktu yang diperlukan untuk mendapatkan permeat sebanyak 5 $\mathrm{mL}$ dicatat sebagai waktu alir dekstran.

Konsentrasi zat terlarut di dalam permeat (Cp), konsentrasi zat terlarut di dalam feed (Cf) dan konsentrasi rentetat $(\mathrm{Cr})$ ditentukan dengan metoda kolorimetri menggunakan spektrofotometer $U V$-Vis. Rejeksi (R) dekstran ditentukan dengan persamaan (2).

Konsentrasi permeat dan retentat serta umpan diukur dengan metode kolorimetri, yaitu dengan menambahkan $5 \mathrm{~mL}$ asam sulfat pekat dan $1 \mathrm{~mL}$ fenol $5 \%$ ke dalam $1 \mathrm{~mL}$ masing-masing larutan dekstran. Sampel diaduk hingga homogen menggunakan Vortec Genie dan dibiarkan pada suhu kamar dan ditentukan absorbansinya menggunakan spektrofotometer $\quad U V$-Vis pada panjang gelombang optimum $(\lambda) 490 \mathrm{~nm}$. Konsentrasi ditentukan dengan mensubstitusikan absorbansi dari: umpan, retentat dan permeat pada kurva kalibrasi larutan standar dekstran $0 ; 25 ; 75 ; 125$; 250 dan 500 ppm. Panjang gelombang gelombang $(\lambda)$ optimum merupakan panjang gelombang yang menghasilkan absorbansi maksimum.

\subsection{Pengujian Selektivitas Rata-rata Secara Statistik}

Untuk menentukan signifikansi perbedaan rata-rata selektivitas air dan destran pada membran hibrid PS/DMAc/PEG-Lempung dan PS/DMAc/PEG-Lempung dilakukan secara statistik menggunakan uji t . Dalam uji $\mathrm{t}$, untuk membedakan nilai rata-rata dari 2 polulasi data, perlu dihitung standar deviasi menggunakan persamaan 3 dan jumlah kuadrat dihitung dengan persamaan 4 (Nazir, 2003). 
$\mathrm{Sx}_{1}-\mathrm{x}_{2}=\sqrt{\frac{S S 1+S S 2}{n 1+n 2-2}} \times \frac{1}{n 1}+\frac{1}{n 2} \ldots \ldots$

$\mathrm{SS}=\sum X i^{2}-\frac{\left(\sum X i\right)^{2}}{n}$

Dalam hal ini, $\mathrm{SS}_{1}=$ Jumlah kuadrat dari sampel 1, $S_{2}=$ Jumlah kuadrat dari sampel 2, $\mathrm{n}_{1}$ dan $\mathrm{n}_{2}=$ Jumlah sampel 1 dan $2, \mathrm{Sx}_{1}-\mathrm{X}_{2}=$ Standar deviasi dari beda, $X i=$ Pengamatan variabel ke-i . Hipotesis pengujian perbandingan nilai tengah populasi dari 2 perlakuan.yang berbeda dinyatakan sebagai berikut :

$$
\begin{aligned}
& \mathrm{H}_{0}: \mu_{1}=\mu_{2} \text { atau } \mu_{1}-\mu_{2}=0 \\
& \mathrm{H}_{1}: \mu_{1} \neq \mu_{2} \text { atau } \mu_{1}-\mu_{2} \neq 0
\end{aligned}
$$

Nilai statistik uji t dihitung dengan persamaan 5

$$
\mathrm{t}=\frac{x 1-\mathrm{x} 2}{\mathrm{Sx} 1-\mathrm{x} 2}
$$

Kriteria pengujian hipotesis

Terima $\mathrm{H}_{\mathrm{o}}$ jika $\mathrm{t}$ hit $\leq \mathrm{t}$ tab, $\mathrm{df}=\mathrm{n}_{1}+\mathrm{n}_{2}-2$

Tolak $\mathrm{H}_{\mathrm{o}}$ jika $\mathrm{t}$ hit $>\mathrm{t}$ tab, $\mathrm{df}=\mathrm{n}_{1}+\mathrm{n}_{2}-2$

\section{Hasil dan Pembahasan}

\subsection{Karakterisasi Selektivitas}

Berdasarkan Tabel 1 diketahui bahwa koefisien rejeksi dekstran dengan BM 400$500 \mathrm{kDa}$ pada kedua membran lebih tinggi dibandingkan dekstran berat molekul 8,5$11,5 \mathrm{kDa}$ (Gambar 4.10). Hasil ini sesuai dengan Mulder (1996) yang menyatakan, selektivitas membran dipengaruhi oleh ukuran molekul yang dipisahkan.

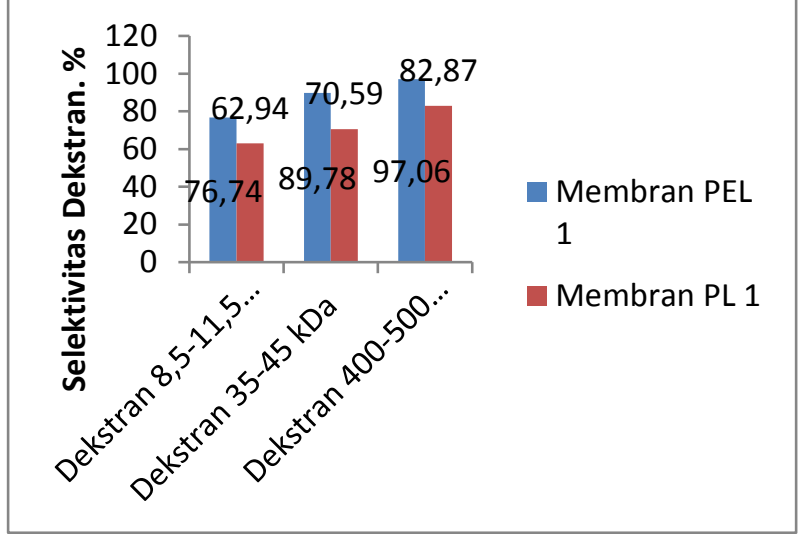

Gambar 1. Perbandingan Selektivitas Dekstran pada Membran Hibrid PS/DMAc/PEGLempung dan PS/DMAc/Lempung

Selektivitas yang tinggi dapat diperoleh jika ukuran partikel terlarut relatif lebih besar dari ukuran pori membran (Mulder, 1996). Oleh karena itu, pada jenis membran yang sama, semakin besar ukuran molekul yang dipisahkan, maka semakin besar fraksi yang dapat tertahan, sehingga semakin besar pula selektivitasnya. Hasil yang sama juga dilaporkan Ahmad (2005), pada pH yang sama koefisien rejeksi dekstran BM besar dari membran polisulfon lebih tinggi dibandingkan dekstran BM rendah.

Pengaruh distribusi pori membran pada koefisien rejeksi dekstran dapat diketahui dari nilai koefisien rejeksi membran hibrid PS/DMAc/PEG-Lempung yang lebih tinggi dibandingkan membran PS/DMAc/Lempung $(97,06 \%>82,77 \%)$, seperti ditunjukkan pada Gambar 1. Hasil ini , juga didukung oleh pengukuran morfologi membran dengan menggunakan SEM (Gambar 2). Dari analisis dengan SEM dapat diketahui, permukaan membran PS/DMAc/PEG-Lempung mempunyai ukuran pori lebih kecil, jumlah pori lebih banyak dan distribusi pori lebih merata dibandingkan membran PS/DMAc/Lempung (Zaiyar,2014). Kondisi ini, menyebabkan membran hibrid PS/DMAc/PEG-Lempung lebih selektif dalam merejeksi dekstran dibandingkan dengan membran hibrid PS/DMAc/Lempung. Hasil ini senada dengan Liu \& Ji (2008), yang melaporkan 
bahwa membran hibrid berpori mempunyai selektivitas tinggi.

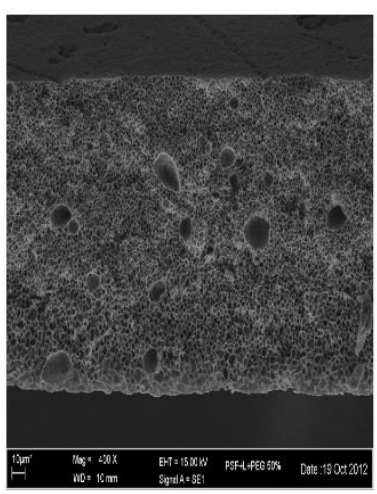

(a)

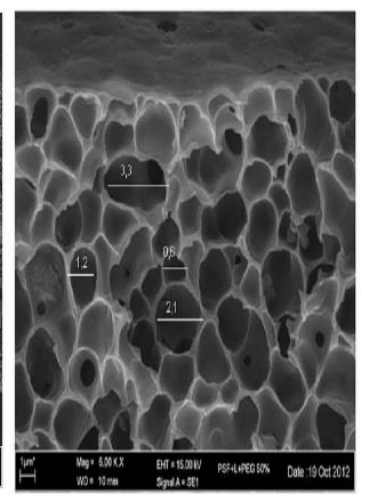

(b)
Gambar 2. Morfologi Membran PS/DMAc/PEGLempung (a) dan PS/DMAc/Lempung (b)

Sumber : Zaiyar (2014)

Berdasarkan uji statistik pada perbedaan koefisien rejeksi antara membran hibrid PS/DMAc/PEG-Lempung dan PS/DMAc/ Lempung menggunakan uji t diperoleh nilai $\mathrm{t}_{\text {hitung }}=19,767>\mathrm{t}_{\text {tabel } 0,05(2)}=4.303$, yang berarti hipotesis $\mathrm{H}_{\mathrm{o}}$; ditolak dan hipotesis $\mathrm{H}_{1}$ diterima $\left(\mathrm{H}_{\mathrm{o}}: \overline{\mu_{1}}=\mu_{2}\right.$ atau $\mu_{1}-\mu_{2}=0$ dan $\overline{\mathrm{H}}_{1}: \mu_{1} \neq \mu_{2}$ atau $\left.\mu_{1}-\mu_{2} \neq 0\right)$. Hal ini menunjukkan bahwa koefisien rejeksi membran PS/DMAc/PEG-Lempung dan PS/DMAc/Lempung berbeda signifikan

Berdasarkan analisis tersebut diketahui selektivitas terhadap dekstran dari membran hibrid ditentukan dari struktur membran yang digunakan pada proses pemisahan. Karakteristik dari non pelarut dan pelarut yang digunakan dalam proses koagulasi berperan dalam mempengaruhi struktur membran yang dihasilkan.

Difusi non pelarut 2-propanol-air ke dalam larutan tuang lebih lambat dibandingkan non pelarut air, namun lebih lambat dibandingkan non pelarut 2-propanol disebabkan koefisien difusi

propanol < 2-propanol-air < air). Pertukaran pelarut dan non pelarut yang berlangsung cepat (pemisahan seketika), pada penggunaan non pelarut air dalam pembuatan membran hibrid polisulfon-lempung menghasilkan membran berstruktur asimetris (Meretsa,2012). Penggunaan non pelarut 2-propanol menghasilkan membran berstruktur simetris (Thurmer et al., 2012). Pada penelitian ini, penggunaan non pelarut 2-propanol-air menghasilkan membran hibrid polisulfon- lempung berstruktur asimetris

Struktur membran hibrid polisulfonlempung yang dihasilkan pada proses inversi fase juga berkaitan dengan koefisien koagulasi. Koefisien koagulasi 2-propanolair $\left(\Delta \delta \mathrm{c}-\mathrm{p}=22,87 \mathrm{Mpa}^{1 / 2}\right)$, lebih rendah dibandingkan koefisien koagulasi air $(\Delta \delta \mathrm{c}-$ $\mathrm{p}=33.43 \mathrm{Mpa}^{1 / 2}$ ), namun lebih tinggi dari koefisien koagulasi 2-propanol $(\Delta \delta \mathrm{c}-\mathrm{p}=$ 12,32 $\left.\mathrm{Mpa}^{1 / 2}\right)$. Hal ini berarti, 2propanol-air mempunyai kemampuan koagulasi yang terletak di antara air dan 2propanol.

Menurut Tomaszewska (1996), struktur membran berpori dihasilkan oleh proses koagulasi yang tertunda, namun, jika koagulasi seketika akan terbentuk lapisan kulit yang rapat. Oleh karena itu, proses koagulasi membran hibrid polisulfonlempung dalam non pelarut 2-propanol-air berada diantara seketika dan tertunda, maka membran hibrid polisulfon-lempung yang dihasilkan adalah berpori kecil dengan jumlah pori lebih banyak dan distribusi pori lebih merata, sehingga menghasilkan koefisien permeabilitas air dan dekstran serta selektivitas dekstran yang lebih tinggi. Hasil ini lebih tinggi dibandingkan Meretsa (2012), pada jenis membran yang sama namun menggunakan non pelarut air. Dari hasil ini, dapat dinyatakan bahwa non pelarut 2-propanol-air dapat meningkatkan selektivitas dekstran.

Menurut Ahmad (2005), membran yang mempunyai kinerja baik adalah membran dengan nilai fluks, koefisien permeabilitas dan koefisien rejeksi juga besar ( $\mathrm{R}>90 \%$ ). Fluks yang besar menunjukkan proses pemisahan berlangsung cepat dan koefisien 
rejeksi yang besar berarti proses pemisahannya berlangsung baik.

Tabel 1. Selektivitas Dekstran pada Membran Hibrid PS/DMAc/PEG-Lempung dan PS/DMAc/Lempung $\left(\mathrm{T}=25 \pm 2{ }^{\circ} \mathrm{C}, \mathrm{P}=1-3,5\right.$ bar $)$

\begin{tabular}{lcccc}
\hline Membran & $\begin{array}{c}\text { Tekanan } \\
\text { Hibrid }\end{array}$ & \multicolumn{2}{c}{ Rejeksi Dekstran, $\%$} & \\
\hline PS/DMAc/ & 1,00 & $8,5-11,5 \mathrm{kDa}$ & $35-45 \mathrm{kDa}$ & $400-500 \mathrm{kDa}$ \\
PEG-Lempung & 1,50 & 48,43 & 84,36 & 90,77 \\
& 2,00 & 70,86 & 85,71 & 92,73 \\
& 3,00 & 75,17 & 87,09 & 93,93 \\
& 3,50 & 76,74 & 88,10 & 95,24 \\
PS/DMAc/ & & & 89,78 & 97,06 \\
Lempung & 1,00 & 34,07 & & 72,17 \\
& 1,50 & 44,88 & 51,72 & 75,00 \\
& 2,00 & 52,82 & 53,74 & 79,87 \\
& 3,00 & 56,49 & 60.26 & 81,37 \\
& 3,50 & 62,94 & 65,13 & 82,77 \\
\hline
\end{tabular}

\section{Kesimpulan}

1. Selektivitas membran hibrid PS/DMAc/PEG-Lempung yang menggunakan PEG dan lempung sebesar $97,06 \%$ dan membran hibrid PS/DMAc/Lempung yang tanpa PEG sebesar $82,77 \%$.

2. Perbedaan komposisi PEG dan lempung mempengaruhi selektivitas membran hibrid.

3. Perbedaan rata-rata koefisien rejeksi membran antara hibrid PS/DMAc/PEGLempung dengan PS/DMAc/Lempung berbeda signifikan.

\section{Daftar Acuan}

Anadao, P, Sato, L.F. Wiebeck, H \& Diaz, F.R.V., 2010, Montmorillonite as Component of Polysulfone Nanocomposite Membranes, Applied Clay Science 48: 127132.

Defontaine, G. Barichard,A. Letaief,S. Feng,C.Matsuura, T \& Detellier,C., 2009, Nanoporous Polymer-Clay Hybrid Membranes For Gas Separation, J.Colloid 15 (2): 622-627.
Liu, X. Peng, Y and Ji, S., 2008, A New Method to Prepare OrganicInorganic Hybrid Membranes, Desalination 221: 376-382. .

Meretsa R., 2012, Pembuatan Membran Hibrid Polisulfon-Lempung Secara Inversi Fase dengan Variasi Waktu Perendaman. Skipsi Jurusan Kimia FMIPA UR, Pekanbaru

Mulder, M., 1996, Basic Principles of Membrane Technology. Second edition. Kluwer Academic Publishers, Dordrecht.

Nadarlis., 2012, Identifikasi dan Karakterisasi Lempung Alam Desa Palas Kecamatan Tampan dan Desa Talanai Teratak Buluh Kecamatan Siak Hulu, Skripsi Jurusan Kimia FMIPA UR, Pekanbaru.

Nazir, M., 2003, Metode Penelitian, Ghalia Indonesia, Jakarta

Thürmer, M.B. Patrícia, P. Marcos, M. Jocelei, D \& Mara, Z., 2012, Effect of Non Solvents Used In The Coagulation Bath on Morphology of PVDF Membranes, Materials Research 15 (6): $1-15$ 
Tomaszewska, M., 1996, Preparation and properties of flat-sheet membranes from poly(vinylidene fluoride) for membrane distillation, Desalination 104 : 1-11.

Zaiyar, 2014, Permeabilitas Air dan Dekstran Membran Hibrid yang Dokoagulasi 2-propanol-air, Sainstek 3 (1) : 29 - 33

Zaiyar, 2014, Pengaruh Zat Aditif pada Membran Hibrid PolisulfonLempung, Photon 4 (2) : $33-38$

Zulfikar, et al., 2006, Synthesis and characterization of poly(methyl
methacrylate)/SiO2 hybrid membranes: Effect of solvents on structural and thermal properties. Journal of Applied Polymer Science. 99: 3163-3171. 